\title{
Systematic effects on morph frequency in the polymorphic mangrove snail Littoraria pallescens
}

\author{
L. M. Cook
}

\author{
Department of Environmental Biology, \\ University of Manchester, \\ Manchester M13 9PL, U.K.
}

General observations of the polymorphic mangrove snail $L$. pallescens suggest that frequencies of the dark morph are lower in places where it shares its leaf habitat with a congeneric species than where it is present alone. The other species involved resemble the dark morph. This possibility was tested by comparing the composition of samples from two genera of mangrove trees which differ in their likelihood of having the alternative species on the leaves. The results showed the same pattern. This is a systematic effect on morph frequency, possibly selective predation, because the colonies on the different species of trees are drawn from the same larval population.

\section{INTRODUCTION}

The factors which maintain visible polymorphisms in a wide range of animal species are imperfectly understood. In molluscs, about 30 per cent of species are polymorphic in some groups, and there is an association of background homogeneity with monomorphism, and heterogeneity with polymorphism (Clarke et al., 1978; Cain, 1977, 1988). An effect of visual predators is implied, and the polymorphism may develop because the background favours an appropriate type of behaviour either on the part of the predators or of the prey (Cook, 1986a). The majority of the work to investigate these factors has probably been carried out on the helicid snail Cepaea nemoralis. The results have only been partially successful (e.g., Clarke $e t$ al., 1978; Jones et al., 1977), and it is still possible to argue that much of the variation in morph frequency is due to random factors (Selander and Ochman, 1983).

A very promising alternative system is presented by the prosobranch genus Littoraria, in which species restricted to uniform root and bark substrates are monomorphic while those restricted to leaves are polymorphic (Reid, 1986). L. pallescens is a polymorphic species which invites comparison with $C$. nemoralis. Both have distinct dark brownish, yellow and reddish morphs. C. nemoralis is widespread in Europe and lives in a wide variety of habitats. It is always polymorphic, but variable in phenotype frequency from one place to another. L. pallescens occurs from east Africa to the western Pacific, but in a rather constant habitat consisting of mangrove trees. It is always polymorphic, but with relatively invariant frequencies, darks being the commonest morph, yellows comprising one quarter to one third of the population and orange about five per cent. Cepaea nemoralis is terrestrial, with low mobility and has a small effective population size (Greenwood, 1975). L. pallescens is effectively terrestrial when it has settled, but has a planktonic larval stage and a high effective population size. In each case, the scale of variation in morph frequencies may be interpreted as a consequence either of effective population size or selection resulting in background matching. In each case there is evidence for selection, but it cannot be said conclusively that it generates the patterns observed.

C. nemoralis has a very similar congener, $C$. hortensis, which is also polymorphic. They are often sympatric, and there is evidence that morph frequencies are more divergent between the two when they are sympatric than when they are allopatric (Clarke, 1962). This may be interpreted as evidence of selective predation, although other selective explanations are possible (Carter, 1967; Clarke, 1969; Clarke et al., 1978).

There are several other Littoraria species which occur sympatrically with $L$. pallescens. In most cases they exhibit sharp habitat separation, living 
almost exclusively on bark on mangrove trees. Bark-living species are monomorphic dark brown, resembling most closely the dark morph of $L$. pallescens. Sometimes, bark-living species extend onto leaves, and occasionally $L$. pallescens is found on bark, although there is strong substrate specificity. The investigation presented here was designed to investigate whether any inter-species effects on morph frequency occur.

The question of inter-species interaction arose from a comparison of morph frequencies in $L$. pallescens from Papua New Guinea and from Kenya. A survey in Papua New Guinea (Cook, 1986b) showed that samples taken over some $100 \mathrm{~km}$ of coast had a rather constant frequency of dark individuals, with a mean of 66.2 per cent (68 samples; the mean and standard error for arcsin transformed frequencies are 56.4 $\pm 0 \cdot 76)$. They were collected in an area where $L$. pallescens is present alone on leaves. In Kenya there is a second sympatric species, L. subvittata, which is monomorphic with diagonal dark stripes (Reid, 1986). It most resembles the dark form of $L$. pallescens and occurs both on bark and on leaves. In January 1988, eight samples were collected over $150 \mathrm{~km}$ of coast, in which the L. pallescens frequencies were homogeneous with $56 \cdot 3$ per cent dark. The transformed frequency is $48 \cdot 4 \pm 3.08$. In these samples the frequency of $L$. subvittata as a fraction of all snails on leaves was 50.8 per cent. Thus, in a region where leaves are also occupied by a second species resembling the dark morph, the frequency of darks in L. pallescens is lower than in an area where it occurs alone. This agrees with an earlier observation by Dr M. A. Beaumont (personal communication), who found even lower frequencies of darks. There are many other reasons why the frequencies should differ between the two regions, but the result suggested that a further test of the hypothesis of interaction should be carried out under better controlled conditions.

\section{MATERIALS AND METHODS}

The survey was carried out on the island of Phuket, in southern Thailand. Mangroves are established in many of the bays on the east and south of the island, with a few small outliers to the west. On the seaward side, the dominant trees are usually Rhizophora apiculata and $R$. mucronata or Avicennia alba and $A$. marina, interspersed with Sonneratia alba. A number of cther species are to be found to landward. Reid (1985) and Frith et al. (1976) describe the vegetation at Ao Nam Bor, where the mangrove is very extensive, and the small mangrove at Ao Yon is described by Hylleberg (1987). Littoraria pallescens is abundant, as is $L$. intermedia, a species which is monomorphic and typically lives on the roots and trunks. It is sometimes to be found on leaves, however, where it closely resembles the dark form of $L$. pallescens.

The survey took place in October and November 1988 in bays around the coast of Phuket Island (Cook and Garbett, 1990). A total of 50 samples was examined, in which morph frequencies were scored. Samples observed on Rhizophora were distinguished from those on Avicennia and scored for morph frequency in $L$. pallescens and ratio of $L$. pallescens to $L$. intermedia in order to test for associations with type of tree. At each site the dominant tree species were either Avicennia or Rhizophora, and in all cases the sample was taken exclusively from leaves of trees of one or other genus.

\section{RESULTS}

The composition of the collections is given in table 1. This shows the number of individuals in each morph category in $L$. pallescens and the number of $L$. intermedia. The frequency of dark in $L$. pallescens, and $L$. intermedia as a fraction of all snails on leaves, are listed. The last column indicates whether the sample was taken from Avicennia or Rhizophora. The sites are listed geographically from northeast of the island (Site 1) to the middle of the west coast (Site 14). Using Kendall's coefficient the correlation of frequency of dark in pallescens with Site numbers is not significant ( Tau $=-0 \cdot 17, t=1 \cdot 74)$, so that there is no evidence that morph frequency varies geographically. Using the Mann-Whitney test, the frequency of $L$. intermedia is found to be significantly higher in samples from Avicennia than in those from Rhizophora ( $z=3.47, P<0.001)$. This is probably because foliage descends lower on Avicennia than on Rhizophora, and L. intermedia is therefore more likely to be forced onto leaves at high tide.

In $L$. pallescens the frequency of the dark morph is significantly lower in samples from Avicennia than in those from Rhizophora $(z=3 \cdot 77$, $P<0.001)$. The result is that intermedia frequency and dark frequency in pallescens are negatively correlated (Kendall's Tau $=-0 \cdot 21, t=2 \cdot 18, P<$ $0 \cdot 05$ ). The relation is shown in fig. 1. It can be seen that samples from Avicennia and Rhizophora are widely distributed among each other, and not 
Table 1 Individuals of two species of Littoraria from sites on Phuket Island, Thailand. Numbers of three morphs of $L$. pallescens are shown, followed by numbers of $L$. intermedia. The next two columns show frequency of dark in $L$. pallescens, and $L$. intermedia as a fraction of total sample. Last column indicates whether sample was from Rhizophora or Avicennia. Sites are, 1: Ban Rak Mai, 2: Phara, 3: Bang Rong, 4: Ban Pa Klok, 5: Ban Sapam, 6 Ao Nam Bor, north, 7: Ao Nam Bor, 8: Laem Phan Wa, 9: Ao Yon, 10: Ao Chalong, east, 11: Ao Chalong, north, 12: Ao Chalong, west, 13: Kata, 14: Ban Layan

\begin{tabular}{|c|c|c|c|c|c|c|c|c|}
\hline \multirow[b]{2}{*}{ Sample } & \multirow[b]{2}{*}{ Site } & \multicolumn{3}{|c|}{ L. pallescens } & \multirow[b]{2}{*}{ L. intermedia } & \multirow[b]{2}{*}{$\%$ dark } & \multirow[b]{2}{*}{$\%$ intermedia } & \multirow[b]{2}{*}{ Mangrove } \\
\hline & & Orange & Yellow & Dark & & & & \\
\hline 1 & 1 & 2 & 10 & 52 & 8 & 81 & 11 & RH \\
\hline 2 & 1 & 0 & 2 & 11 & 17 & 84 & 56 & AV \\
\hline 3 & 1 & 0 & 2 & 46 & 11 & 95 & 18 & RH \\
\hline 4 & 1 & 0 & 3 & 12 & 13 & 80 & 46 & AV \\
\hline 5 & 2 & 1 & 4 & 23 & 10 & 82 & 26 & RH \\
\hline 6 & 2 & 2 & 2 & 26 & 26 & 86 & 46 & RH \\
\hline 7 & 3 & 0 & 3 & 3 & 54 & 50 & 90 & RH \\
\hline 8 & 3 & 0 & 3 & 18 & 42 & 85 & 66 & RH \\
\hline 9 & 3 & 0 & 1 & 9 & 85 & 90 & 89 & RH \\
\hline 10 & 4 & 1 & 9 & 23 & 44 & 69 & 57 & $\mathrm{AV}$ \\
\hline 11 & 4 & 0 & 6 & 18 & 28 & 75 & 53 & AV \\
\hline 12 & 5 & 1 & 6 & 13 & 64 & 65 & 76 & AV \\
\hline 13 & 6 & 1 & 5 & 33 & 13 & 84 & 25 & RH \\
\hline 14 & 6 & 0 & 2 & 21 & 14 & 91 & 37 & RH \\
\hline 15 & 7 & 0 & 2 & 29 & 17 & 93 & 35 & RH \\
\hline 16 & 7 & 1 & 17 & 68 & 8 & 79 & 8 & RH \\
\hline 17 & 7 & 1 & 10 & 64 & 1 & 85 & 1 & RH \\
\hline 18 & 7 & 1 & 12 & 94 & 8 & 87 & 6 & $\mathrm{RH}$ \\
\hline 19 & 7 & 2 & 36 & 207 & 63 & 84 & 20 & RH \\
\hline 20 & 7 & 0 & 8 & 62 & 22 & 88 & 23 & RH \\
\hline 21 & 8 & 5 & 63 & 132 & 44 & 66 & 18 & AV \\
\hline 22 & 8 & 1 & 51 & 123 & 47 & 70 & 21 & $\mathrm{AV}$ \\
\hline 23 & 9 & 0 & 8 & 92 & 5 & 92 & 4 & RH \\
\hline 24 & 9 & 1 & 1 & 38 & 12 & 95 & 23 & AV \\
\hline 25 & 9 & 2 & 2 & 35 & 5 & 89 & 11 & RH \\
\hline 26 & 9 & 0 & 3 & 72 & 1 & 96 & 1 & RH \\
\hline 27 & 9 & 0 & 6 & 38 & 11 & 86 & 20 & RH \\
\hline 28 & 9 & 1 & 8 & 56 & 5 & 86 & 7 & RH \\
\hline 29 & 9 & 4 & 7 & 73 & 2 & 86 & 2 & RH \\
\hline 30 & 10 & 2 & 13 & 64 & 0 & 81 & 0 & RH \\
\hline 31 & 10 & 1 & 7 & 33 & 2 & 80 & 4 & AV \\
\hline 32 & 10 & 0 & 6 & 37 & 9 & 86 & 17 & AV \\
\hline 33 & 10 & 0 & 21 & 55 & 0 & 72 & 0 & RH \\
\hline 34 & 10 & 4 & 28 & 74 & 2 & 69 & 1 & RH \\
\hline 35 & 11 & 4 & 19 & 78 & 0 & 77 & 0 & RH \\
\hline 36 & 11 & 1 & 8 & 87 & 0 & 90 & 0 & RH \\
\hline 37 & 11 & 1 & 16 & 90 & 4 & 84 & 3 & $\mathrm{RH}$ \\
\hline 38 & 11 & 1 & 16 & 66 & 33 & 79 & 28 & AV \\
\hline 39 & 11 & 2 & 12 & 59 & 4 & 80 & 5 & $\mathrm{RH}$ \\
\hline 40 & 11 & 0 & 10 & 74 & 4 & 88 & 4 & RH \\
\hline 41 & 12 & 2 & 11 & 47 & 24 & 78 & 28 & $\mathrm{AV}$ \\
\hline 42 & 12 & 0 & 10 & 45 & 44 & 81 & 44 & AV \\
\hline 43 & 12 & 0 & 27 & 13 & 23 & 32 & 36 & AV \\
\hline 44 & 12 & 0 & 14 & 14 & 33 & 50 & 54 & AV \\
\hline 45 & 12 & 0 & 11 & 22 & 54 & 66 & 62 & AV \\
\hline 46 & 12 & 4 & 25 & 44 & 46 & 60 & 38 & AV \\
\hline 47 & 12 & 0 & 7 & 14 & 56 & 66 & 72 & AV \\
\hline 48 & 13 & 3 & 9 & 42 & 11 & 77 & 16 & $\mathrm{RH}$ \\
\hline 49 & 13 & 0 & 8 & 70 & 5 & 89 & 6 & $\mathrm{RH}$ \\
\hline 50 & 14 & 1 & 13 & 56 & 14 & 80 & 16 & AV \\
\hline
\end{tabular}

clumped into particular parts of the distribution. A negative correlation would be expected if, for example, predators selected for a modal frequency determined by frequency of background elements, and did not distinguish between the two species. If that were so, the frequency of dark in the two species taken together should be more uniform than in $L$. pallescens alone. Using arcsin 


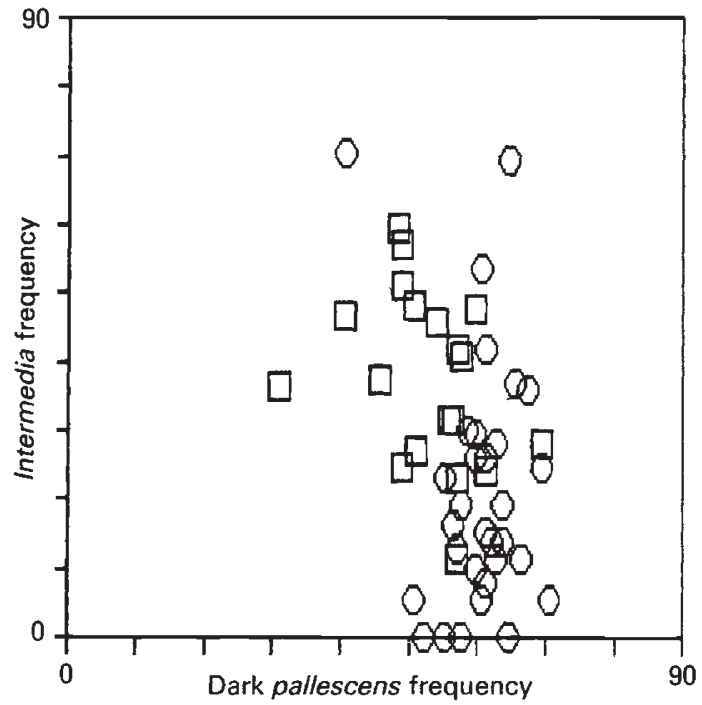

Figure 1 Relation of fraction of $L$. intermedia in sample to fraction of dark in $L$. pallescens (arcsin transformed frequencies). Rectangles: samples from Avicennia, circles: samples from Rhizophora.

transformed data this is found to be the case $(F=1.73, P<0.05)$.

\section{DISCUSSION}

The general correlation of polymorphic species with foliage-living and of monomorphic species with bark-living in the genus Littoraria (Reid, 1986) appears to favour selection as an explanation for polymorphism, but it could be suggested that the foliage habitat removes the animals from predation pressure, so that variant mutant forms are not eliminated (Rosewater, 1970). The only practical way of countering this possibility is to show that systematic forces are at work. Seasonal changes in morph frequency have been demonstrated by Hughes and Mather (1986), Reid (1987) and Cook (1986b). There are differences in heating properties and shell strength between the morphs (Reid, 1987; Cook and Freeman, 1986; Cook et al., 1985; Cook, 1990). Evidence for apostatic selection has been obtained in the similar polymorphic species $L$. filosa (Reid, 1987), although predators have not been caught in the act of selection.

Associations of morph frequency with local features are also good evidence for systematic effects. Reid (1987) demonstrated that dark $L$. filosa has a higher frequency on bare Avicennia trees and yellows on leafy trees, which suggests visual selection for crypsis. The positive result reported here is that morph frequency in $L$. pallescens appears to compensate for the presence of another species, L. intermedia, which looks like one of the morphs. This supports the prediction from the earlier comparison between frequencies in two regions. It could be an effect of predators selecting for a modal morph frequency. Alternatively, the conditions which lead more $L$. intermedia to utilize the leaves of Avicennia than of Rhizophora could also favour the non-dark morphs of $L$. pallescens. Since the individuals on Avicennia and Rhizophora are recruited from the same larval population and are replenished by annual spawning, a systematic effect of some kind must be involved.

Acknowledgements This work was supported by the Bonhote Fund of the Linnean Society, the Percy Sladen Memorial Fund and the British Ecological Society. Observations in Kenya were made possible by a grant from the Nuffield Foundation. I am grateful to them and to the Director and staff of the Phuket Marine Biological Center for the opportunity to work there, and thank S. D. Garbett for his assitance with the project.

\section{REFERENCES}

CAIN, A. J. 1977. The uniqueness of polymorphism of Cepaea (Pulmonata: Helicidae) in western Europe. J. Conch., 29, 129-136.

CAIN, A. J. 1988. The colours of marine bivalve shells with special reference to Macoma balthica. Malacologia, 28, 289-318.

CARTER, M. A. 1967. Selection in mixed colonies of Cepaea nemoralis and Cepaea hortensis. Heredity, 22, 117-139.

CLARKE, B. 1962. Natural selection in mixed populations of two polymorphic snails. Heredity, 24, 347-352.

CLARKE, B., ARTHUR, W., HORSLEY, D. T. AND PARKIN, D. T. 1978. Genetic variation and natural selection in pulmonate molluscs. In Fretter, V. and Peake, J. (eds) Pulmonates. Vol. 2A, Systematics, Evolution and Ecology, Academic Press, New York, pp. 219-270.

COOK, L. M. 1986a. Polymorphic snails on varied backgrounds. Biol. J. Linn. Soc., 29, 89-99.

COOK, L. M. 1986b. Site selection in a polymorphic mangrove snail. Biol. J. Linn. Soc., 29, 101-113.

COOK, L. M. 1990. Differences in shell properties between morphs of Littoraria pallescens. Hydrobiologia, 193, 217 221.

COOK, L. M., CURREY, J. D. AND SARSAM, V. H. 1985. Differences in morphology in relation to microhabitat in littorinid species from a mangrove in Papua New Guinea (Mollusca: Gastropoda). J. Zool. Lond., 206, 297-310.

COOK, L. M. AND FREEMAN, P. M. 1986. Heating properties of morphs of the mangrove snail Littoraria pallescens. Biol. J. Linn. Soc., 29, 295-300.

COOK, L. M. AND GARBETT, S. D. 1990. Patterns of variation in mangrove littorinid molluscs on Phuket Island. Phuket Mar. Biol. Center Res. Bull.

FRITH, D. W., TANTANASIRIWONG, R. AND BHATIA, O. 1976. Zonation of macrofauna on a mangrove shore, Phuket Island. Phuket Mar. Biol. Centre Res. Bull., 10, 1-37. 
GREENWOOD, J. J. D. 1975. Effective population numbers in the snail Cepaea nemoralis. Evolution, 28, 513-526.

HUGHES, J. M. AND MATHER, P. B. 1986. Evidence for predation as a factor in determining shell colour frequencies in a mangrove snail Littoraria sp. (Prosobranchia: Littorinidae). Evolution, 40, 68-77.

HYLLEBERG J. (ed) 1987. Ao Yon-a mangrove in the Andaman Sea. Institute of Ecology and Genetics, University of Aarhus, Denmark. 75pp.

JONES, J. S., LEITH, B. H. AND RAWLINGS, P. 1977. Polymorphism in Cepaea: A problem with too many solutions. $A$. Rev. Ecol. Syst. 8, 109-143.

REID, D. G. 1985. Habitat and zonation patterns of Littoraria species (Gastropoda: Littorinidae) in Indo-Pacific mangrove forests. Biol. J. Linn. Soc., 26, 39-68.
REID, D. G. 1986. The Littorinid Molluscs of Mangrove Forests in the Indo-Pacific Region: The Genus Littoraria. British Museum (Natural History), London, 228pp.

REID, D. G. 1987. Natural selection for apostasy and crypsis acting on the shell colour polymorphism of a mangrove snail, Littoraria filosa (Sowerby) (Gastropoda: Littorinidae). Biol. J. Linn. Soc., 30, 1-24.

ROSEWATER, J. 1970. The family Littorinidae in the IndoPacific. Part I. The subfamily Littorininae. Indopacific Mollusca, 2, 417-506.

SELANDER, R. K. AND OCHMAN, H. 1983. The genetic structure of populations as illustrated by molluscs. In Isozymes: Current Topics in Biological and Medical Research. Vol. 10: Genetics and Evolution, Liss, New York, pp. 93-123. 